\title{
Acúmulo de Reservas Internacionais e Fluxo de Capital Estrangeiro
}

\section{International Reserves Accumulation and the Foreign Capital Flow}

\author{
Wilfredo L. Maldonado* \\ Washington Martins da Silva**
}

Resumo: Observações empíricas revelam a dependência inversa entre o risco país e a taxa de acúmulo de reservas internacionais no Brasil. A partir disto, este trabalho propõe um modelo teórico para explicar a relação entre o acúmulo de reservas internacionais e o fluxo de capital estrangeiro no país. Simulações numéricas com esse modelo mostram esse fato estilizado. Finalmente, fazemos o ajuste não linear entre o fluxo de capital estrangeiro e a taxa de perda de reservas internacionais para vários períodos no intervalo janeiro de 1995 a dezembro de 2010. Os resultados mostram que uma política parcimoniosa de acúmulo de reservas internacionais é uma estratégia eficiente para captação de recursos e, portanto de proteção contra flutuações externas.

Palavras-chave: Reservas internacionais. Fluxo de Capital Estrangeiro. Modelos com possibilidade de inadimplência.

Abstract: Empirical observations show the inverse relationship between country risk and the rate of international reserves accumulation in Brazil. From this, we propose a theoretical model explaining the link between the accumulation of international reserves and the foreign capital flow in the country. Numerical simulations performed from this model show that stylized fact. Finally, we make the nonlinear fitting between the foreign capital flow and the rate of loss of international reserves for several periods in the interval January 1995 to December 2010. The results show that a parsimonious policy of international reserves accumulation is an efficient strategy for fundraising and therefore protection against external fluctuations.

\footnotetext{
* Professor da Pós-Graduação em Economia da Universidade Católica de Brasília. E-mail: wilfredo@pos.ucb.br Este autor agradece o apoio financeiro do CNPq (Brasil) através dos processos 305317/2003-2 e 472178/2006-7.

* * Pós-Graduação em Economia da Universidade Católica de Brasília. E-mail: martins.washington@ gmail.com
} 
Keywords: International reserves. Foreign capital flow. Models with default.

JEL Classification: E22, F22.

\section{1 lntrodução}

Uma das variáveis macroeconômicas que tem recebido destaque na economia internacional nos últimos anos é o nível de Reservas Internacionais (RI). Nos países em desenvolvimento este nível tem aumentado significativamente nos últimos anos, fenômeno percebido em menor escala nos países desenvolvidos.

Reservas internacionais são depósitos que os Bancos Centrais guardam em moeda estrangeira que resultam do balanço de pagamentos como a diferença entre o saldo das transações correntes e a conta de capital e financeira. Variações menores destas reservas também podem ser observadas cada vez que o país resolve operar no mercado de câmbio. De acordo com o Relatório de Gerenciamento das Reservas Internacionais do Brasil do Banco Central (Bacen), o país acumula reservas internacionais com o intuito de aumentar sua capacidade de enfrentar crises internacionais.

No Gráfico 1, observa-se o estoque de reservas internacionais para o Brasil de janeiro de 1995 a dezembro de 2010. O Brasil vinha mantendo um estoque em média de US\$ 46 bilhões até 2005, após este período o nível de reservas passou para patamares em torno de US $\$ 200$ bilhões chegando a dezembro de 2008 a US\$ 288 bilhões.

Gráfico 1 - Estoque de reservas internacionais, conceito liquidez - Brasil (US\$ bilhões)

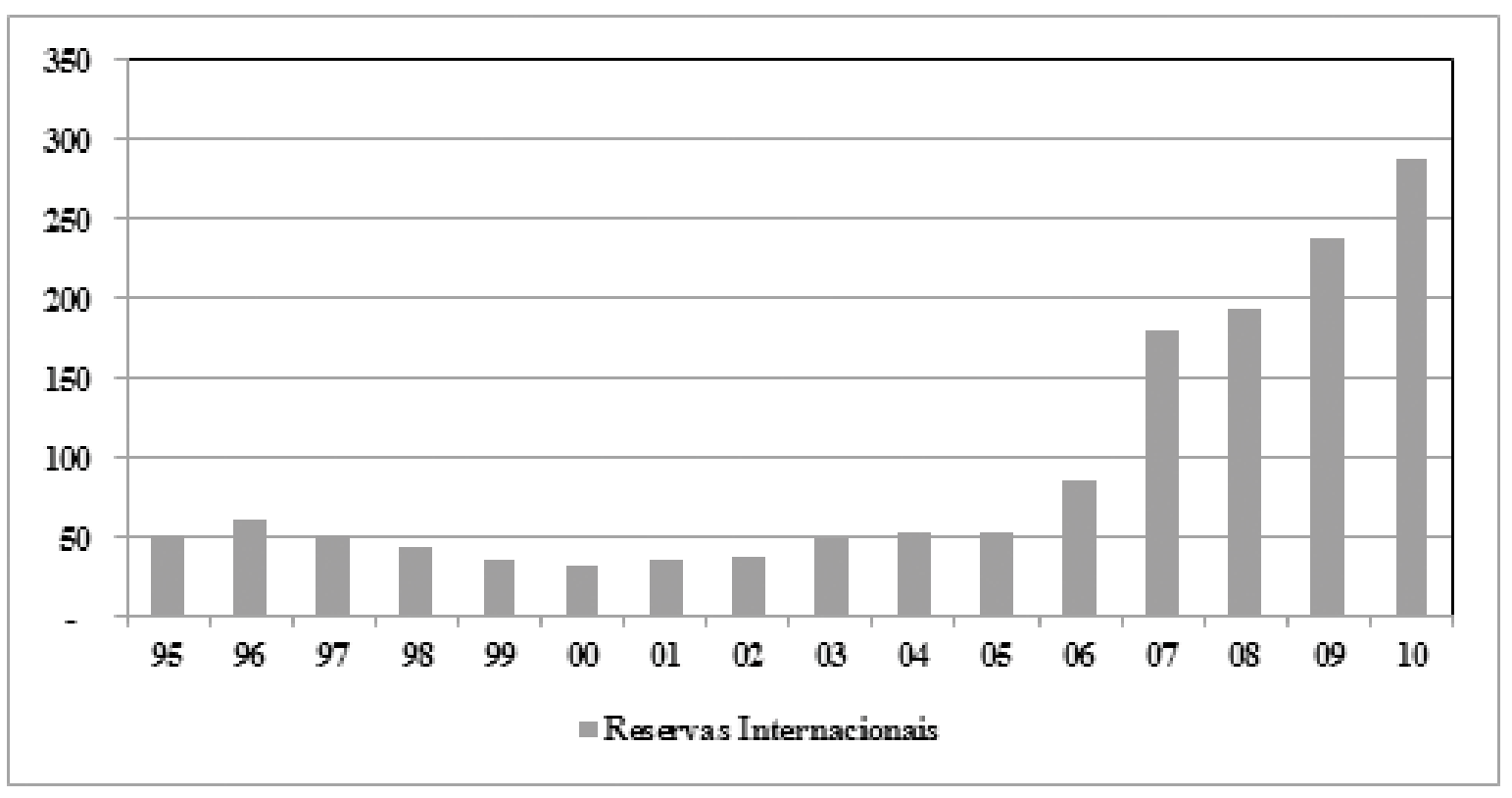

Fonte: Banco Central do Brasil. 
Este acúmulo de reservas observado nos últimos anos não foi exclusivo do Brasil. Países em desenvolvimento adotaram também essa estratégia especialmente após as crises da Ásia e da Rússia. No Gráfico 2, observam-se os dez países com maiores estoques de reservas internacionais do mundo em 2010. Atualmente, a China é o país com maior quantidade de reservas internacionais no mundo com US $\$ 2.648$ bilhões. Os países do leste asiático são, hoje, os maiores detentores de reservas internacionais.

Aizenman e Marion (2003) buscaram explicações para o aumento da demanda por reservas internacionais dos países do leste asiático. De acordo com os autores, a recente escalada no acúmulo de reservas internacionais nos países da Ásia pode ser explicada por motivos precaucionais. Os autores focaram dois entre os vários fatores que influenciam o aumento das reservas internacionais: o primeiro é a necessidade de suavizar o consumo e distorções intertemporais em face ao acesso condicional ao mercado global de capital e o alto custo de coletar recursos na economia doméstica. O segundo é o aumento da volatilidade dos choques e/ou aumento da aversão às perdas depois da crise financeira de 1997/1998.

Gráfico 2 - Países com maiores estoques de reservas internacionais em 2010 (US\$ bilhões)

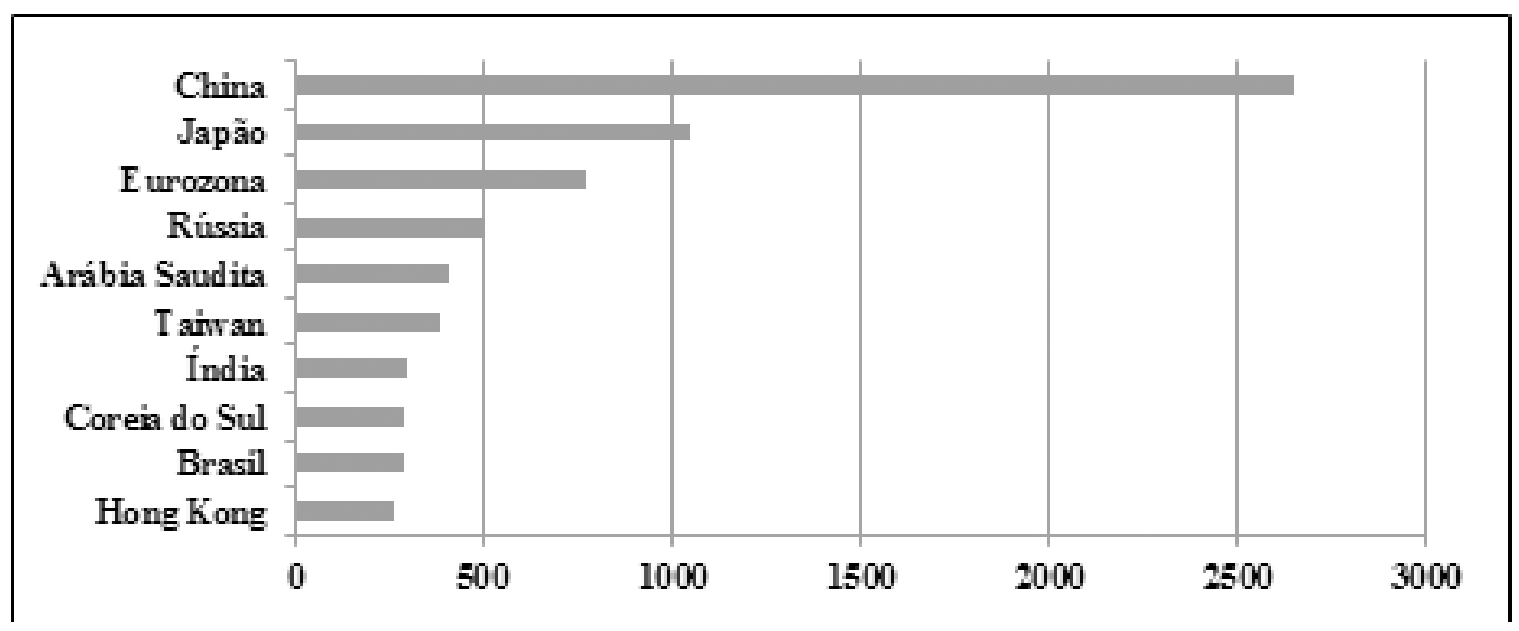

Fonte: Data Template on International Reserves and Foreign Currency Liquidity Reporting Countries. Imf.org.

Durdu et al. (2009) apresentaram algumas estimativas do nível ótimo de poupança precaucional acumulada por uma pequena economia aberta em resposta à volatilidade do ciclo dos negócios, globalização financeira e risco de paradas súbitas. Nesse estudo os autores concluíram que a globalização financeira e o risco de paradas súbitas podem ser uma explicação plausível para o aumento das reservas nos países emergentes.

Jeanne e Ranciere (2011) apresentaram um modelo ótimo do nível de reservas internacionais para pequenas economias abertas procurando segurança 
contra paradas súbitas no fluxo de capital estrangeiro. Contudo, a quantidade de reservas internacionais acumuladas pelos países da Ásia parece exceder o nível ótimo de reservas encontrado pelo modelo contra paradas súbitas.

O comum denominador desses trabalhos é a conclusão de que o recente e acentuado aumento no acúmulo de reservas por parte dos países em desenvolvimento tem como finalidade a suavização do consumo e precaução contra eventuais paradas súbitas nos fluxos de capitais estrangeiros, o que teria como consequência a diminuição no produto.

O fluxo de capital estrangeiro é calculado na conta capital e financeira do balanço de pagamentos. Os principais itens dessa conta são os Investimentos Estrangeiros Diretos (IED), e os investimentos em carteira. O IED pode ser considerado mais desejado pelos países por ser destinado ao setor produtivo e tem uma característica de longo prazo. Já os investimentos em carteira também permitem que as firmas captem recursos via empréstimos ou abertura de capital e isto também beneficia indiretamente o setor produtivo da economia, porém sofre de uma volatilidade maior.

O Gráfico 3 mostra a dinâmica do fluxo mensal de capital estrangeiro (FCAP) acumulado anualmente no período de janeiro de 1995 a dezembro de 2010. Observa-se no gráfico que a tendência de crescimento sempre é interrompida em períodos de crise. De 1996 para 1997, há uma queda no fluxo de capitais para o país, período em que houve a crise Asiática. De 1998 para 1999 verifica-se outra diminuição no fluxo de capitais, período este em que ocorreu a crise Russa em 1998 e a crise brasileira em 1999. No período de 2001 a 2002 ocorreram diversos choques internacionais e nacionais, quais sejam: crise Argentina, que declarou moratória de sua dívida externa e ataque terrorista às torres gêmeas nos EUA, ambos em 2001, a crise energética do Brasil e a instabilidade eleitoral que começou em outubro de 2002. Depois desses eventos os fluxos voltaram a oscilar com uma queda acentuada de 2007 para 2008, período que eclodiu a crise do subprime. 
Gráfico 3 - Fluxo de capital estrangeiro no Brasil, 1995 a 2010 (US\$ bilhões)

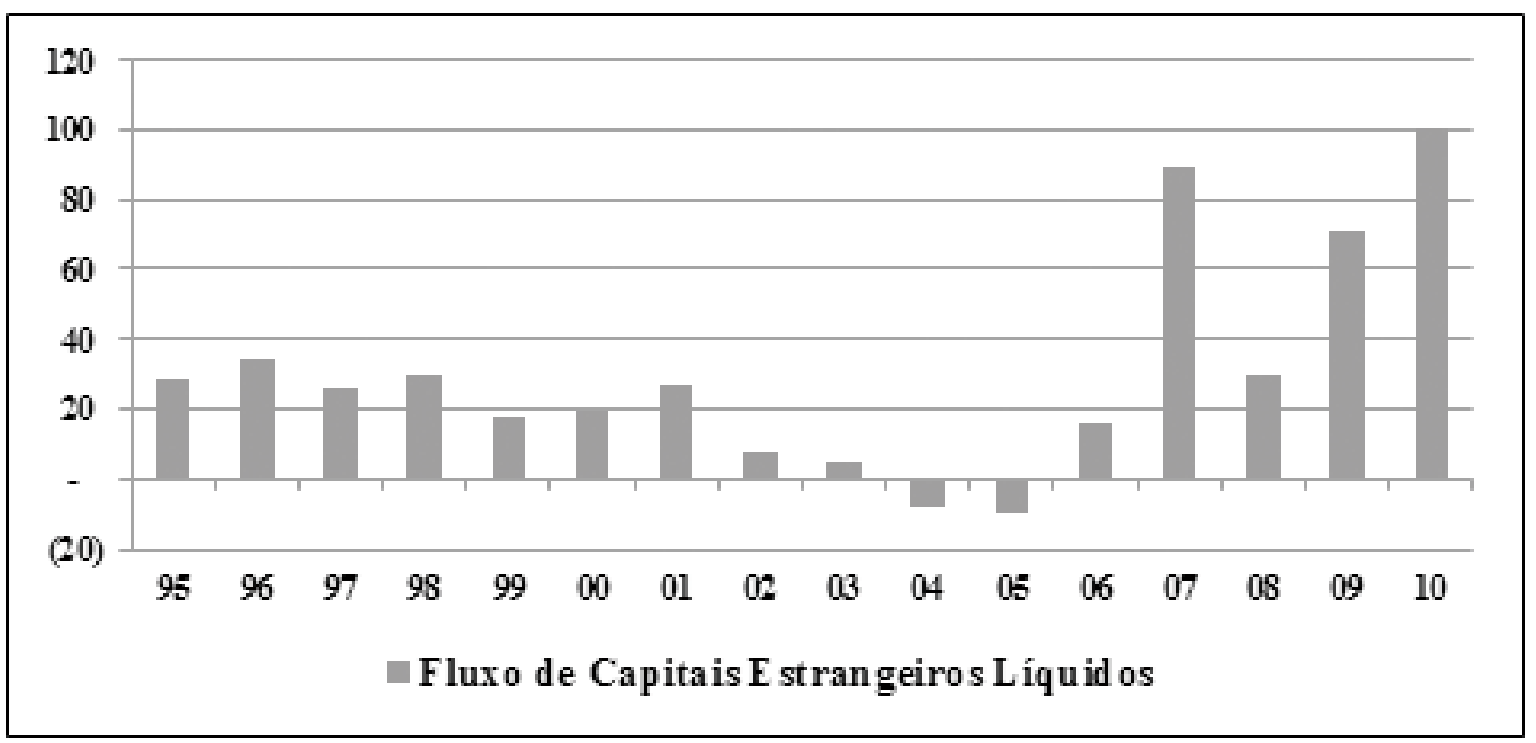

Fonte: Banco Central do Brasil.

Os fluxos de capitais estrangeiros têm várias variáveis como determinantes. Dentre elas temos as taxas de retorno (de longo e curto prazo), a taxa de câmbio ou expectativa de desvalorização e o risco político, vindo de mudanças de política de governo em relação ao controle da movimentação dos capitais externos. $\mathrm{O}$ propósito deste trabalho é verificar que de fato o acúmulo de RI agrega todas estas variáveis de maneira que o fluxo de capitais depende positivamente neste acúmulo.

O acúmulo de RI tem um efeito colateral: incentivo ao investimento no país. Os capitais estrangeiros buscam direcionar os seus fluxos a países com fundamentos sólidos e que mostrem condições de honrar os seus compromissos financeiros. Nesta linha de raciocínio, Maldonado et al. (2007), propuseram uma relação empírica onde o fluxo de capital estrangeiro (FCAP) depende da expectativa de taxa de perdas de reservas internacionais (RLSFRES ${ }^{\mathrm{e}}$ ). Os autores ajustaram uma relação não linear entre essas variáveis e a utilizaram para analisar impactos de políticas de comércio internacional sobre a economia brasileira.

Choi et al. (2009) examinaram a relação linear entre o fluxo líquido e capital estrangeiro e as reservas internacionais. Nesse estudo foi encontrado que o fluxo líquido de capital estrangeiro passou de negativo para positivo nos países em desenvolvimento, mas não para os países desenvolvidos. Os resultados empíricos sugerem que os países em desenvolvimento recentemente tem se preocupado com as súbitas interrupções dos fluxos de capital, acumulando níveis de reservas internacionais cada vez maiores. Por outro lado, nos países desenvolvidos com acesso aos mercados internacionais, o crescimento das reservas tem sido menor. 
Estudos buscam identificar quais são os determinantes dos fluxos de capitais estrangeiros. Kim (2000) utiliza um modelo VAR estrutural para investigar as causas do fluxo de capital estrangeiro em quatro países em desenvolvimento: México, Chile, Coreia e Malásia. Ele encontrou que as causas do fluxo de capital, para estes países, estão menos relacionadas a fatores internos, como choques de produtividade e de demanda agregada, e cada vez mais ligado a fatores externos como diminuição das taxas de juros internacionais e recessão nos países industriais. Indicando assim, que os países em desenvolvimento devem ficar atentos ao cenário econômico externo e procurar manter princípios macroeconômicos sólidos.

Barbosa e Meurer (2010) analisaram quais variáveis macroeconômicas têm mais influência sobre o fluxo de capital estrangeiro no Brasil. Foram utilizados dados trimestrais no período de 1995 a 2009. Os resultados mostram que as variáveis mais influentes são: as taxas de juros internacionais, o risco cambial, a variação do risco-país e o crescimento do PIB. Segundo os autores a distinção entre regime de câmbio fixo e flutuante, as crises financeiras e os estoques acumulados de investimento estrangeiro em carteira não foram variáveis explicativas para a oscilação do fluxo de capitais.

Val e Libânio (2010) analisaram a volatilidade dos fluxos financeiros e a fuga de capitais no Brasil como medidas de instabilidade financeira e vulnerabilidade externa desta economia. Eles apontam que os eventos externos fora do controle das autoridades domésticas, acentuam a volatilidade dos fluxos de capitais, influenciando o desempenho da economia brasileira e limitando a eficácia da política macroeconômica.

Paula et al. (2003) argumentam que o controle do fluxo de capitais estrangeiros aumenta a autonomia da política monetária e reduz a vulnerabilidade externa das economias emergentes. Em sua exposição os autores citam o Chile no período de (1991-1998) e Malásia (a partir de 1998) como dois exemplos de casos efetivos de controle de capitais para limitar os fluxos de curto prazo.

Nessa mesma linha de controle de capitais, Silva (2004) apresenta um modelo macrodinâmico com o objetivo de demonstrar que o controle de capitais influencia positivamente o desempenho macroeconômico das economias emergentes. Segundo o autor controle no fluxo de capitais permite uma taxa de juros de longo prazo mais baixo, uma aceleração na taxa de crescimento do produto e um aumento do nível de utilização da capacidade produtiva.

O objetivo deste trabalho é verificar a relação positiva entre estas duas variáveis macroeconômicas: $\mathrm{O}$ acúmulo de reservas internacionais e o fluxo de capitais estrangeiros. Para isto propomos um modelo de consumo-investimento de dois períodos onde interagem uma economia pequena e o resto do mundo, Mostramos que o aumento do acúmulo de reservas que a economia pequena decida carregar de um período para o outro implica num aumento do fluxo de 
capitais de equilibrio para esta economia. Posteriormente estimamos a relação não linear proposta por Maldonado et al. (2007) para o período de janeiro de 1995 a dezembro de 2010, separando em intervalos onde esta relação mostra acentuada estabilidade e proporcionamos uma explicação para tal estabilidade.

O artigo é dividido em quatro seções. Na seção 2 apresentamos uma evidência empírica de como a taxa de perda de RI está correlacionada com o risco do país. Isto é feito para motivar o modelo de consumo-investimento que explica a relação entre o fluxo de capitais externos e o acúmulo de RI. Nele uma pequena economia demanda capital do resto do mundo o qual assume que poderá sofrer default por parte dela. A partir das equações de equilíbrio desse modelo realizamos um exercício de estática comparativa que mostra o nosso resultado teórico principal. Na seção 3 é feito o ajuste de uma relação não linear entre o fluxo de capital externo e a taxa de perda de RI. Finalmente, na seção 4 são apresentadas as principais conclusões do trabalho.

\section{Taxa de Perda de Reservas Internacionais e o Fluxo de Capitais Externos: um Modelo Teórico}

Os detentores de capital estrangeiro tomam suas decisões de investimento com base no risco e retorno. A percepção de risco, ou possibilidade de decretar moratória do país, é levada em consideração na hora em que o investidor estrangeiro toma sua decisão de aplicar seus recursos em determinado país. Iniciaremos esta seção com uma comprovação empírica de que a taxa de perda de RI que um país tem é uma variável determinante na percepção de risco da economia.

Para isto é estimada a relação (linear) entre estas duas variáveis. Especificamente para o risco do país utiliza-se como proxy o índice de títulos da dívida de mercados emergentes EMBI+, calculado pelo JPMorgan, conhecido pelo mercado como risco-país. Esta variável é regredida contra a taxa de perda de RI. Podemos observar no Gráfico 4 a relação entre essas duas variáveis.

A relação proposta é a seguinte ${ }^{1}$ :

$$
\text { Risco }_{t}=\alpha+\beta * \text { RLSFRES }_{t}+\delta * D_{t}+\varepsilon_{t}
$$

Utilizamos uma dummy de nível no período do subprime, compreendendo o período de outubro de 2008 a maio de 2009. Os Resultados encontrados encontram-se na equação (2).

$$
\text { Risco }_{\mathrm{t}}=\underset{(26,1)}{294,1}+\underset{(28,3)}{105,9} * \operatorname{RLSFRES}_{\mathrm{t}}+\underset{(37,3)}{132,1} * \mathrm{D}_{\mathrm{t}}
$$

$1 \quad$ Foram feitos testes incluindo dummies de intercepto e de inclinação, mas o segundo não se mostrou significativo, por isto reportamos somente a dummy de intercepto. 
Gráfico 4 - Risco Brasil e taxa de perda de reservas- janeiro de 2005 a agosto de 2010

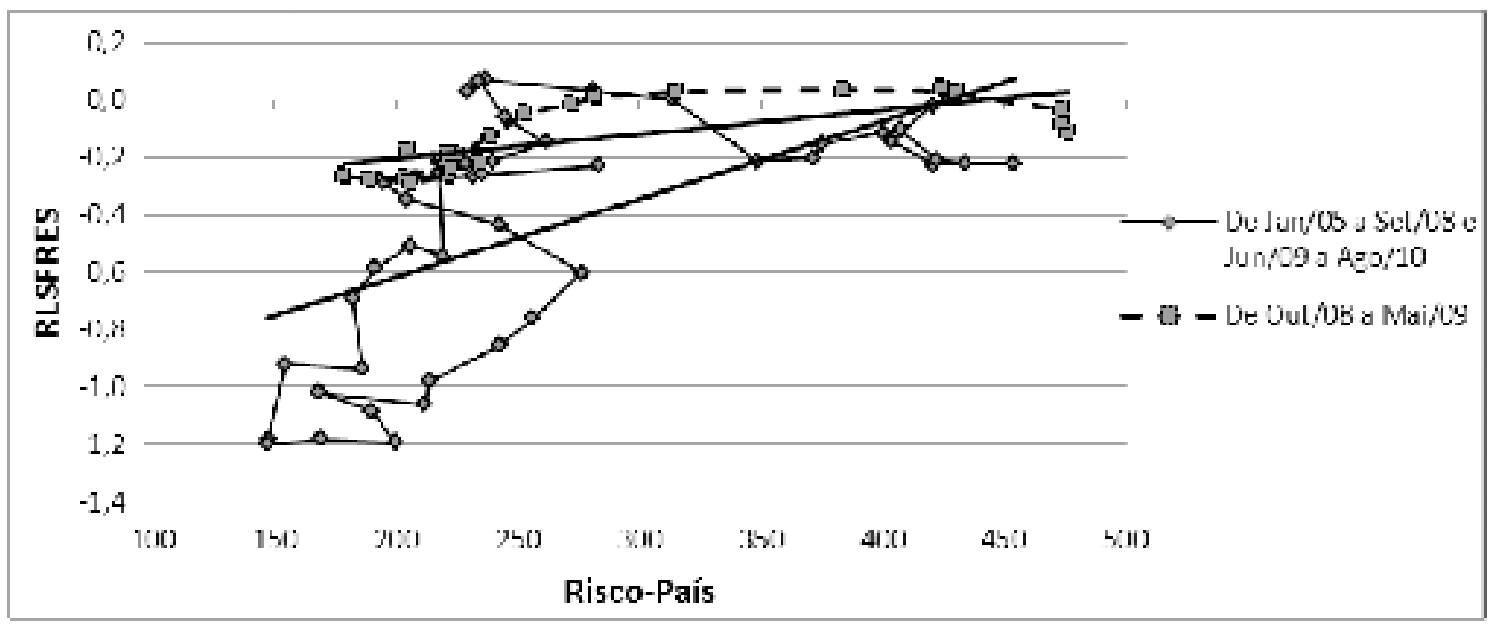

Fonte: Elaboração própria.

A regressão foi estimada pelo método MQO, utilizando a matriz de NeweyWest para correção de heterocedasticidade e autocorreção. Todos os parâmetros foram significativos ao nível de $1 \%$. O coeficiente de determinação ajustado ficou em $47 \%$. Desta forma verificamos que um aumento de $1 \%$ na taxa de perda de RI imprimirá um aumento de 105,9 pontos na percepção de risco de mercado e, portanto haverá uma diminuição no fluxo de capital estrangeiro.

\subsection{Modelo Teórico}

A seguir, construímos um modelo teórico que permitirá justificar essa relação inversa entre o fluxo de capital estrangeiro e a taxa de perda de reservas internacionais.

Consideremos uma economia aberta com dois períodos: $t=0$ e 1 e um mercado de crédito composto por dois agentes: um credor e devedor. O credor é o agente detentor de capital, chamado em nosso modelo de Resto do Mundo - Rest of the World (ROW), e o devedor, chamado de Pequena Economia Aberta - Small Open Economy (SOE), que recebe o empréstimo (fluxos de capitais) no período $t=0$ devolvendo este valor corrigido no período $t=1$. No período $t=1$, existem $S$ possíveis estados da natureza que representam a incerteza no modelo; um estado genérico é representado por $s$.

O ROW decide o volume de capital que emprestará para a SOE, recebendo juros provenientes destes empréstimos no seguinte período. Por outro lado, a SOE recebe no primeiro período fluxos de capitais estrangeiros, aumentando sua utilidade, e acumula uma quantidade de reservas internacionais (-LSFRES). No segundo período a SOE devolve os fluxos de capitais estrangeiros corrigidos e recebe a quantidade de reservas internacionais corrigida a taxas de juros internacionais. A SOE acumula reservas com o intuito de suavizar o consumo e se proteger con- 
tra possíveis choques externos. A seguir, descrevemos as variáveis e dinâmica do modelo para cada agente.

\subsubsection{Resto do mundo - ROW}

Em $t=0$ decide o volume de empréstimos $\mathrm{m}^{\circ}$ e $\hat{m}^{\circ}$ para a SOE e para os países do ROW respectivamente;

Em $t=1$ recebe $\left(1+r_{S}\right) m^{\circ} t \rho_{s}$, da SOE e $R \hat{m}^{o}$ dos outros países do resto do mundo, onde:

$r_{S}$ é a taxa de juros dos empréstimos para a SOE,

$\rho_{\mathrm{S}}$ é a taxa de pagamento que o ROW recebe da SOE,

$R$ é a taxa de juros dos empréstimos aos países do ROW.

\subsubsection{Pequena economia aberta - SOE}

Em $t=0$ demanda empréstimos $m^{d}$. Além disso, acumula RI, que trataremos como menos a perda de reservas internacionais, (-LSFRES).

Em $t=1$, recebe o retorno dessas reservas $-R(L S F R E S)$ do ROW. Além disso, decide o volume da dívida que irá devolver $D_{S}$, ou seja, estamos supondo que a SOE pode não honrar os seus compromissos financeiros na sua totalidade.

\subsubsection{O Problema da SOE}

Se $u$ é a utilidade instantânea do agente SOE e $\beta$ o fator de desconto então a $\mathrm{SOE}$ resolve o seguinte problema de maximização ${ }^{2}$

$$
\operatorname{Max}_{C_{0}, \tilde{C}, m^{d}, \tilde{D}} u\left(C_{0}\right)+\beta E[u(\tilde{C})]-\lambda E\left[(1+\tilde{r}) m^{d}-\tilde{D}\right]
$$

Sujeito a:

$$
\begin{gathered}
P_{0} C_{0}-e \text { LSFRES }=P_{0} w_{0}+m^{d} \\
P_{s} C_{s}+D_{s}=P_{s} w_{s}-e L S F R E S \\
0 \leq D_{s} \leq\left(1+r_{s}\right) m^{d}
\end{gathered}
$$

Na equação (3), a SOE escolhe o consumo corrente $C_{0}$, o consumo futuro $\tilde{C}$, a demanda por empréstimos $m^{d}$ e a parte da dívida que irá devolver $\tilde{D}$ de modo a maximizar sua utilidade intertemporal. A equação (4) é a restrição orçamentária do primeiro período, onde, dada a dotação inicial dada $w_{0}$ e o acúmulo de reservas (-LSFRES), a SOE escolhe o seu consumo e a demanda por emprés-

2 Utilizaremos a seguinte notação: a variável aleatória $\widetilde{x}$ assume no estado $s$ o valor $x_{s}$. 
timos. A variável e é a taxa de câmbio, suposta constante por simplicidade. A equação (5) é a restrição orçamentária do segundo período e nela observamos como a dotação inicial $w_{s}$ mais o retorno das RI, - eLSFRES, é distribuída no gasto em consumo e no pagamento de parte da dívida $D_{s}$, que no máximo será igual a $\left(1+r_{S}\right) m^{d}$, como descrito na desigualdade em (6). Se a SOE não paga toda a dívida adquirida, ela sofrerá uma penalidade $\lambda E\left[(1+\tilde{r}) m^{d}-\tilde{D}\right]$ na sua utilidade. O parâmetro $\lambda$ é a taxa de penalidade para cada unidade monetária que a SOE deixa de pagar.

É importante destacar que neste modelo, o acúmulo de reservas é resultado de transações anteriores e/ou política de governo, portanto mantido constante na resolução do modelo.

O equilíbrio, para soluções interiores, da SOE é dado pelas condições de primeira ordem:

$$
\begin{gathered}
u^{\prime}\left(C_{0}\right)\left(-\frac{1}{P_{0}}\right)-\lambda E(1+\tilde{r})=0 \\
\beta u^{\prime}(C)\left(-\frac{1}{\tilde{P}}\right)+\lambda=0
\end{gathered}
$$

Resolvendo as equações anteriores junto com as restrições orçamentárias obtemos o seguinte:

$$
\begin{aligned}
& m^{d}=P_{0}\left\{\left(u^{\prime}\right)^{-1}\left(P_{0} \lambda E[(1+\tilde{r})]\right)-w_{0}-e \frac{\text { LSFRES }}{P_{0}}\right\} \\
& D_{s}=P_{s}\left\{w_{s}-e R \frac{\text { LSFRES }}{P_{s}}-\left(u^{\prime}\right)^{-1}\left(\beta^{-1} \lambda P_{s}\right)\right\}
\end{aligned}
$$

A equação (9) nos diz que o fluxo de capital estrangeiro que a SOE vai demandar depende, entre outras variáveis, negativamente da perda de reservas internacionais.

A equação (10) indica a decisão ótima de pagamento de dívida, $D_{s}$ que a SOE vai reembolsar o ROW no segundo período. Observa-se uma relação inversa entre este pagamento de dívida (delivery) e a perda de reservas internacionais. Assim, um aumento na quantidade de reservas internacionais no primeiro período aumenta o delivery que a SOE vai pagar no segundo período. 


\subsubsection{O Problema do ROW}

Por simplicidade, suporemos que a utilidade e o fator de desconto intertemporal do ROW são os mesmos que os da SOE. Desta maneira, o problema dele é:

$$
\operatorname{Max}_{\mathrm{C}_{0}, \tilde{C}, m^{o}} u\left(C_{0}\right)+\beta E[u(\tilde{C})]
$$

Sujeito a:

$$
\begin{gathered}
P_{0}^{f} C_{0}+m^{o}+\hat{m}=P_{0}^{f} w_{0}^{f} \\
P_{s}^{f} C_{s}=P_{s}^{f} w_{s}^{f}+\left(1+r_{s}\right) m^{o}+R \hat{m}
\end{gathered}
$$

Na restrição orçamentária do primeiro período (equação (12)) temos que a riqueza $P_{0}^{f} w_{0}^{f}$ é distribuída em consumo e investimento na SOE e no próprio ROW. Já na restrição (13) a riqueza é formada por aquela vinda das dotações iniciais $P_{s}^{f} w_{s}^{f}$, os retornos dos empréstimos ao resto do mundo $R \hat{m}$, e os retornos dos empréstimos a SOE descontados pela taxa de inadimplência (ou seja, corrigidos pela taxa de pagamento $\left.\rho_{s}\right)$ e dados por $\left(1+r_{s}\right) m^{\circ} \rho_{s}$. A hipótese de economia pequena implica que as variáveis $R$ e $\hat{m}$, que num ambiente geral deveriam ser calculadas em equilíbrio também, serão consideradas constantes (parâmetros) neste modelo.

Podemos reescrever a maximização (11) com as restrições (12) e (13) da seguinte maneira:

$$
\operatorname{Max}_{m^{o}} u\left(w_{0}^{f}-\frac{m^{o}}{P_{0}^{f}}-\frac{\hat{m}}{P_{0}^{f}}\right)+\beta E\left[u\left(\tilde{w}^{f}+\frac{(1+\tilde{r}) \tilde{\rho} m^{o}}{\tilde{P}^{f}}+\frac{R \hat{m}}{\tilde{P}^{f}}\right)\right]
$$

Assim, a condição de primeira ordem resulta:

$$
u^{\prime}\left(C_{0}^{f}\right)\left(-\frac{1}{P_{0}}\right)+\beta E\left[u^{\prime}(\tilde{C})(1+\tilde{r}) \frac{\tilde{\rho}}{\tilde{P}^{f}}\right]=0
$$

A equação (15) define implicitamente $m^{0}$. Observa-se que a quantidade ótima de capital estrangeiro que o ROW irá ofertar para a SOE depende, entre outras variáveis, da taxa de juros $\tilde{r}$ e da taxa de pagamentos $\tilde{\rho}$. 


\subsubsection{A taxa de pagamento}

A taxa de pagamento de empréstimos que o ROW recebe da SOE é:

$$
\rho_{s}=\frac{D_{s}}{\left(1+r_{s}\right) m^{d}}
$$

$\rho_{s}$ depende de $\mathrm{D}_{s}$ que,como vimos na equação (9), depende do parâmetro LSFRES e também depende da demanda por fluxos de capitais estrangeiro $m^{d}$, que pela equação (8), também depende do mesmo parâmetro LSFRES.

\subsubsection{Equilíbrio da economia}

Um equilíbrio para o modelo proposto é uma variável aleatória taxa de juros $\tilde{r}$ que cumpre o seguinte:

a) dada $\tilde{r}$, a SOE demanda a quantidade ótima de recursos, $m^{d}$ no primeiro período e toma a sua decisão ótima de entrega $\tilde{D}$, para o segundo período segundo as equações (9) e (10);

b) a taxa de pagamento é definida por (16);

c) dada $\tilde{r}$ e $\tilde{\rho}$, o ROW toma a sua decisão ótima de oferta de empréstimos segundo a equação (15);

d) a demanda de empréstimos é igual à oferta, ou seja, $m^{d}=m^{0}$.

Como ilustração, podemos considerar dois estados $(S=2)$, fixar a taxa de juros no primeiro deles e variar a taxa de juros no segundo. O Gráfico 5 mostra a demanda e oferta de empréstimos ao variarmos a taxa de juros no segundo estado. A taxa de juros de equilíbrio entre oferta e demanda de empréstimos é representada por re. Quando a perda de RI (LSFRES) aumenta; a partir da equação (9) concluímos que a curva de demanda $\mathrm{m}^{d}$ se desloca verticalmente para abaixo para a nova posição $\mathrm{m}^{\mathrm{d}}$. Esse mesmo aumento na perda de RI pode fazer com que a taxa de pagamento $\rho_{2}$ aumente ou diminua. Se ela diminuir, a oferta de empréstimos $m^{0}$ irá diminuir, o que definitivamente fará com que a oferta de capitais de equilíbrio diminua. Porém, se essa taxa de pagamento aumentar, pode se dar o caso da oferta de capitais subir para $\mathrm{m}^{0}$, como mostra o Gráfico 5 . Nesse caso, o fluxo de capital de equilíbrio poderia aumentar ou diminuir.

Assim, executaremos um exercício numérico mostrando um conjunto de valores plausíveis para os parâmetros do modelo para os quais a resposta do fluxo de capitais de equilíbrio a aumentos na perda de reservas internacionais seja negativa. 


\subsection{Exercício Numérico}

Para realizar este exercício utilizaremos a seguinte função de utilidade:

$$
u(C)=C-\left(\frac{\delta}{2}\right) C^{2} ; \operatorname{com} \delta>0
$$

Em $t=1$ consideraremos dois estados: $s=1,2$, para cada estado é atribuído uma probabilidade $\pi_{s}$.

O acúmulo de reservas internacionais é representado no modelo pela variável $z=$-LSFRES.

2.2.1 Demanda de empréstimos e decisão de pagamento

Com a função de utilidade considerada temos explicitamente a demanda por capitais e a decisão de entrega no segundo período:

$$
\begin{gathered}
m^{d}=P_{0}\left[\frac{1}{\delta}-\frac{\lambda P_{0} E\left[1+r_{s}\right]}{\delta}-w_{0}+\frac{e z}{P_{0}}\right] \\
D_{s}=P_{s}\left[w_{s}+\lambda \frac{P_{s}}{\delta \beta}-\frac{1}{\delta}+\frac{e R z}{P_{s}}\right]
\end{gathered}
$$


Gráfico 5 - Determinação da taxa de juros e volume de capital de equilíbrio

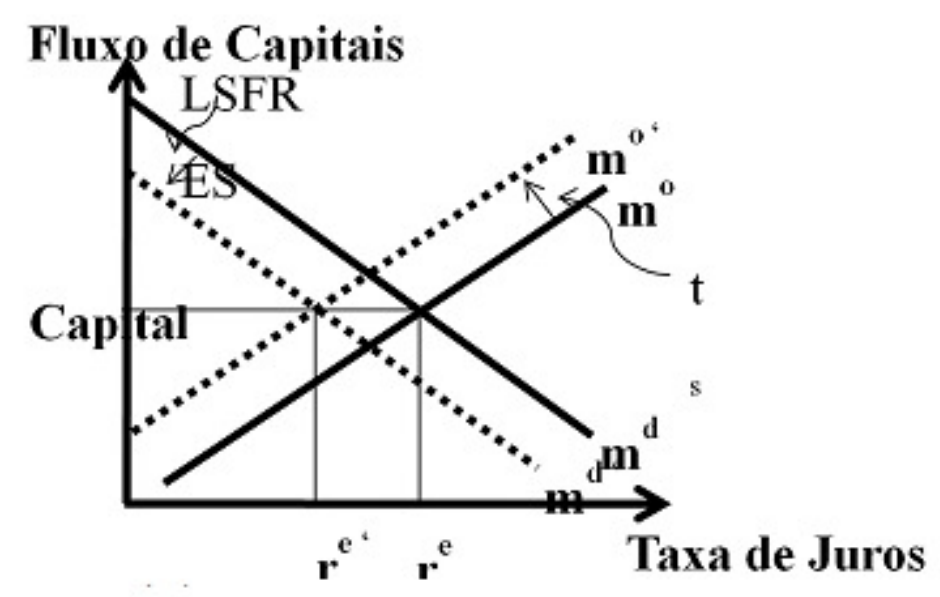

Fonte: Elaboração própria

\subsubsection{Oferta de empréstimos}

Devido à forma quadrática da utilidade, é possível calcular, a partir da equação (15), explicitamente a oferta de capitais do ROW, ela resulta:

$$
m^{o}=\frac{\frac{1}{P_{0}^{f}}-\beta E\left[\frac{(1+\tilde{r}) \tilde{\rho}}{\tilde{P}^{f}}\right]-\frac{\delta}{P_{0}^{f}}\left(w_{0}^{f}-\frac{\hat{m}}{P_{0}^{f}}\right)+\beta \delta E\left[\left(\tilde{w}^{f}+\frac{R \hat{m}}{\tilde{P}^{f}}\right)\left(\frac{(1+\tilde{r}) \tilde{\rho}}{\tilde{P}^{f}}\right)\right]}{-\frac{\delta}{\left(P_{0}^{f}\right)^{2}}-\beta \delta E\left[\frac{(1+\tilde{r}) \tilde{\rho}}{\tilde{P}^{f}}\right]^{2}}
$$

Para a simulação numérica definimos os valores dos parâmetros dados na Tabela 1. Embora eles não pretendam ser aproximações da economia real, são valores plausíveis tanto para o país como para o resto do mundo.

Tabela 1 - Valores dos parâmetros utilizados na simulação computacional

\begin{tabular}{cccc}
\hline Parâmetro & Descrição & Probabilidade & Valor \\
\hline$P_{0}$ & Preço do bem na SOE em $t=0$ & 1 & 1 \\
$P_{1}$ & Preço do bem na SOE em $t=1$ no estado $s=1$ & 0,3 & 1,05 \\
$P_{2}$ & Preço do bem na SOE em $t=1$ no estado $s=2$ & 0,7 & 1,06 \\
$P_{0}^{f}$ & Preço do bem no ROW em $t=0$ & 1 & 1 \\
$P_{1}^{f}$ & Preço do bem no ROW em $t=1$ no estado $s=1$ & 0,3 & 1,01 \\
$P_{2}^{f}$ & Preço do bem no ROW em $t=1$ no estado $s=2$ & 0,7 & 1,02 \\
\hline & & & (continua...)
\end{tabular}




\begin{tabular}{cccc}
\hline$w_{0}$ & Dotação da SOE em $t=0$ & 1 & 100 \\
$w_{1}$ & Dotação da SOE em $t=1$ no estado $s=1$ & 0,3 & 101 \\
$w_{2}$ & Dotação da SOE em $t=1$ no estado $s=2$ & 0,7 & 102 \\
$w_{0}^{f}$ & Dotação do ROW em $t=0$ & 1 & 500 \\
$w_{1}^{f}$ & Dotação do ROW em $t=1$ no estado $s=1$ & 0,3 & 505 \\
$w_{2}^{f}$ & Dotação do ROW em $t=1$ no estado $s=2$ & 0,7 & 510 \\
$R$ & Rendimento Bruto internacional & 1 & 1,01 \\
$\delta$ & Parâmetro da Função Quadrática & 1 & 0,0011 \\
$\lambda$ & Taxa de penalidade da inadimplência & 1 & 0,80 \\
$\beta$ & Fator de desconto intertemporal & 1 & 0,90 \\
$e$ & Taxa de câmbio & 1 & 1,00 \\
$Z$ & Acúmulo de reservas internacionais (-RLSFRES) & 1 & 10 \\
$\hat{m}_{\mathrm{m}}$ & Liquidez internacional & 1 & $-83,42$ \\
$r_{1}$ & Taxa de juros no estado $s=1$ & 0,3 & 0,05 \\
$r_{2}$ & Taxa de juros no estado $s=2$ & 0,7 & 0,051 \\
\hline
\end{tabular}

Fonte: Elaboração própria.

\subsection{Resultados Numéricos}

A partir das formas funcionais e parâmetros definidos acima, foram encontrados os seguintes valores de equilíbrio para a economia:

Um valor para a taxa de juros de 5,15\% e para a taxa de pagamentos de $95 \%$.

a) Com essa taxa de juros a SOE está demandando a quantidade ótima de recursos de 54,67 no primeiro período, e tomando sua decisão de entrega ótima 54,86 para o segundo período. Com esta decisão ótima, a SOE entra em default em 5\%.

b) O resto do mundo está tomando sua decisão ótima de ofertar 54,67 de empréstimos no primeiro período, com base nessa taxa de juros $5,15 \%$, e essa taxa de pagamento $95 \%$;

O Gráfico 6 mostra as curvas de oferta e demanda para os valores dos parâmetros considerados. Para isto fixamos a taxa de juros no primeiro estado da natureza e variamos $r_{2}$. 
Gráfico 6 - Determinação do equilíbrio

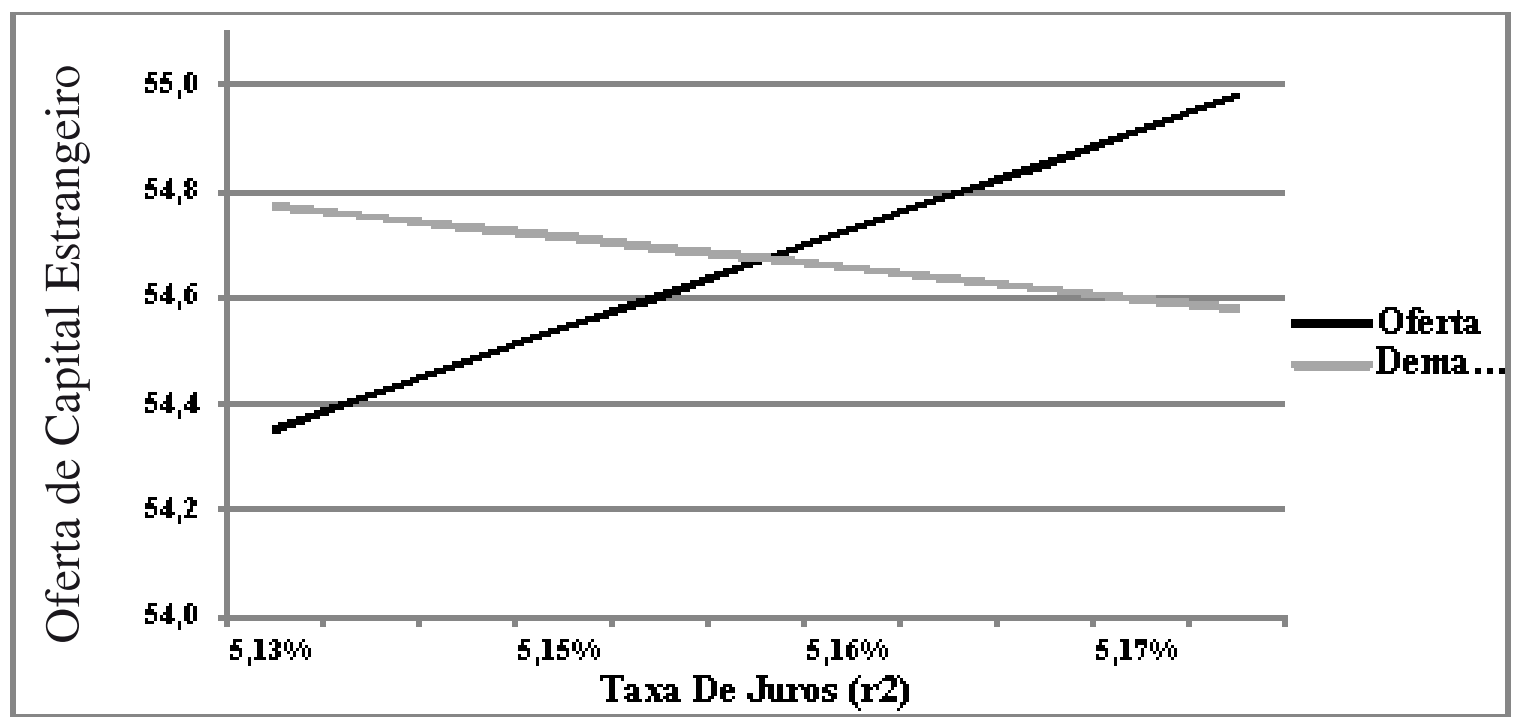

Fonte: Elaboração própria.

Finalmente verificamos a resposta da oferta de empréstimos de equilíbrio (fluxo de capital) a variações no acúmulo de reservas. Para isto, variamos o parâmetro $z=-L S F R E S$ e calculamos o novo equilíbrio da economia. Este exercício de estática comparativa realizado numericamente reportou o Gráfico 7.

Assim, conforme pode ser observado no Gráfico 7, a oferta de capital estrangeiro respondeu positivamente a alterações no acúmulo de reservas internacionais.

Gráfico 7 - Oferta de capital estrangeiro como função do acúmulo de reservas internacionais

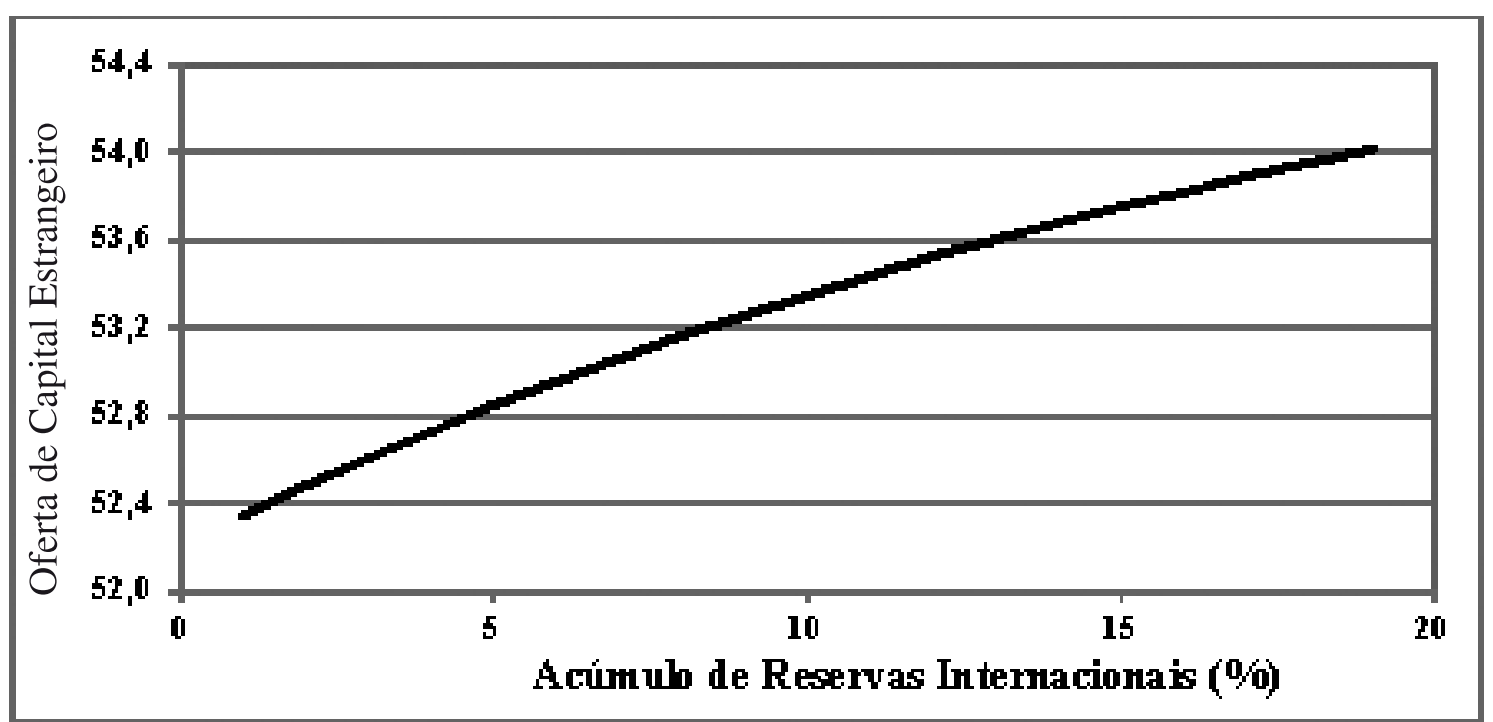

Fonte: Elaboração própria. 


\section{Ajuste da Curva RLSFRES - FCAP}

Com o resultado numérico obtido a partir do modelo teórico construído na Seção 2, procederemos nesta seção a estimar uma relação linear entre a taxa de perda de reservas internacionais e o fluxo de capital estrangeiro. Utilizaremos a mesma forma funcional proposta por Maldonado et al. (2007), entretanto contemplando um período maior de dados.

A oferta de capital estrangeiro proposta no trabalho citado acima é a seguinte:

$$
F C A P_{t}=f\left(R L S F R E S_{t}^{e}\right)=f\left(1-\frac{F R E S_{t}^{e}}{F R E S_{t-1}}\right)
$$

Onde FCAP = o fluxo de capitais estrangeiros, $R L S F R E S^{e}=$ a Taxa de perda esperada de reservas internacionais do país, FRES $\mathrm{t}$ é o nível de reservas internacionais no período t e o supra índice $e$ representa o valor esperado. Suporemos expectativas racionais, de maneira que o valor esperado coincide com o valor observado dessa variável. A função $f$ é estritamente decrescente e estritamente côncava e dada por:

$$
f(x)=a_{1}+a_{2} x-\sqrt{a_{3} x^{2}+a_{4} x+a_{5}}
$$

A função deve ser decrescente, pois a relação estudada entre FCAP com RLSFRES é negativa. A função é estritamente côncava, explicitando que os agentes financeiros são avessos ao risco.

Os dados de fluxo de capitais estrangeiros foram retirados da série 8260 (Conta capital e Financeira líquida) do balanço de pagamentos do Banco Central do Brasil no período de janeiro de 1995 a dezembro de 2010. Estes são dados mensais de fluxos anuais.

Os dados de Reservas Internacionais foram retirados da série 3546 - Reservas internacionais - Conceito liquidez - Total - mensal - US\$ (milhões) do Banco Central do Brasil no período de janeiro de 1995 a dezembro de 2010. Também neste caso temos séries mensais de taxas de variação anual de perdas de reservas internacionais. 


\subsection{Períodos de Estimação}

No intervalo de 15 anos considerado nesta pesquisa, mudanças estruturais na economia e crises alteraram a magnitude ou intensidade da relação, porém não comprometeram o formato não linear entre as variáveis.

Para captar essa relação, os dados foram separados em quatro períodos que mostram relações estáveis entre as variáveis e que estão separados, pelo que percebemos, por mudanças estruturais. O primeiro período com 40 observações foi de janeiro de 1995 a março de 1999, quando a crise da Rússia provocou um deslocamento da curva para um novo patamar, O segundo período com 42 observações foi de abril de 1999 a setembro de 2002, época em que o FED responde à crise causada pelo ataque às torres gêmeas com um forte corte nos juros. O terceiro período com 42 observações foi de junho de 2003 a novembro de 2006 quando começa o segundo governo Lula e o quarto período com 39 observações de junho de 2007 a julho de 2010. O Gráfico 8 mostra as séries de dados destacando cada um dos períodos descritos.

Dois pequenos conjuntos de dados foram expurgados do estudo. Dado todo o período de amostra, estes dados foram os únicos que, por conta das turbulências internacionais, destoaram muito dos padrões observados. Foram retiradas oito observações, compreendendo o período entre outubro de 2002 e maio de 2003, período de instabilidade da economia com a eleição e posse do Lula em seu primeiro mandato. Outros poucos dados foram retirados, seis observações entre dezembro de 2006 a maio de 2007. Período que antecede de turbulência internacional e pouco antes de ser deflagrada a crise do subprime.

Gráfico 8 - Relação entre FCAP e RLSFRES por períodos (US\$ milhões)

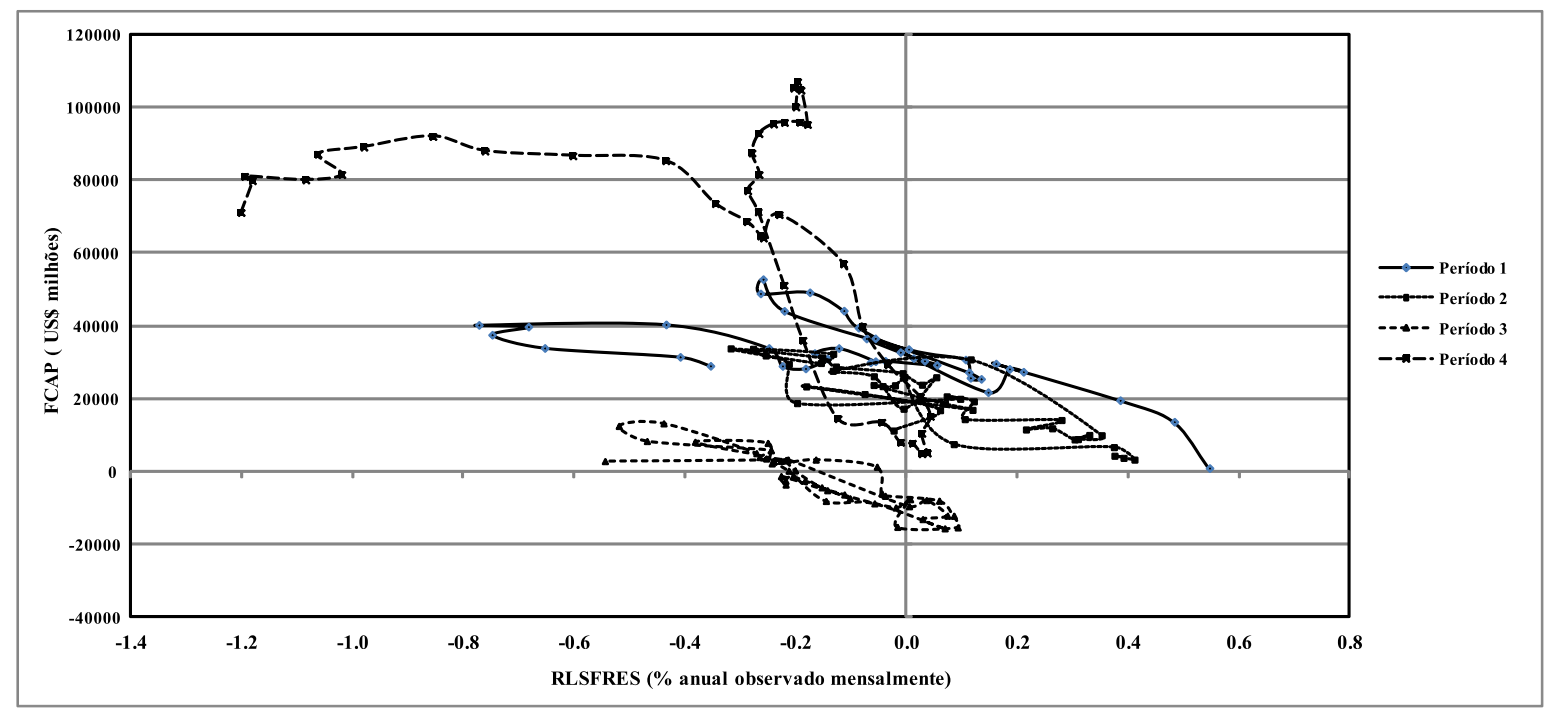

Fonte: Elaboração própria com dados do Banco Central do Brasil. 


\subsection{Estimação e Inferência}

A equação (22) foi estimada para cada um dos quatro períodos. No Gráfico 9 se mostra o resultado.

Neste primeiro período fica clara a relação inversa entre o FCAP e as RLSFRES. A curva se ajustou bem aos dados, conforme pode ser observado no Gráfico 9. Mesmo com a presença de três grandes crises financeiras de repercussão internacional, a crise asiática, em 1997, pela crise russa, em 1998, e pela crise brasileira, em janeiro de 1999 a relação se manteve bastante estável.

Gráfico 9 - Estimação para o $1^{\circ}$ período (janeiro de 1995 a março de 1999) (US\$ milhões)

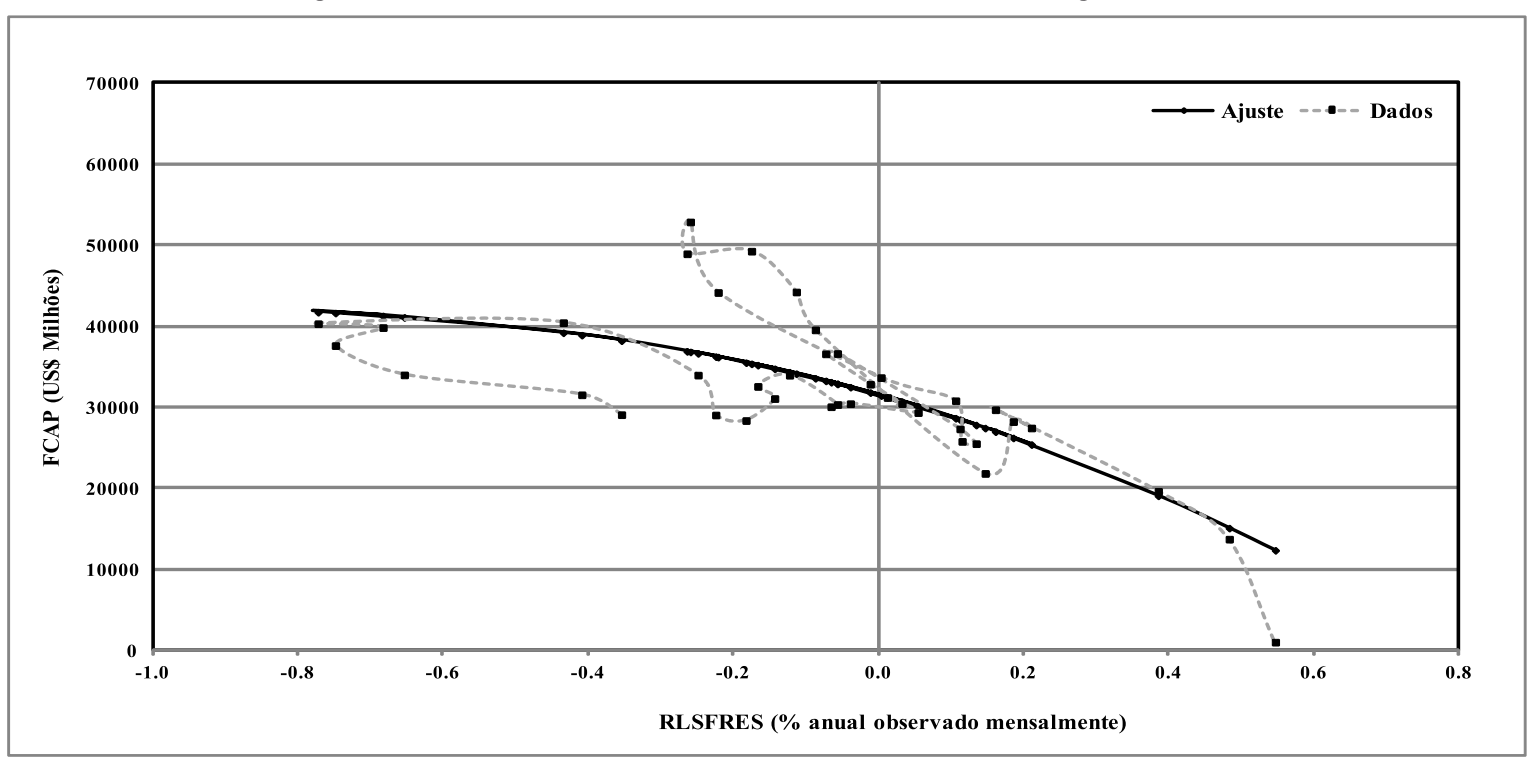

Fonte: Elaboração própria com dados do Banco Central do Brasil.

Depois da crise brasileira em 1999, até a instabilidade política enfrentada pela eleição e posse do governo Lula, a o fluxo de capital estrangeiro apresentou uma nova dinâmica, que foi capturada e bem ajustada a nossa função, como pode ser visto no Gráfico 10. 
Gráfico 10 - Estimação para o $2^{\circ}$ período

(abril de 1999 a setembro de 2002) (US\$ milhões)

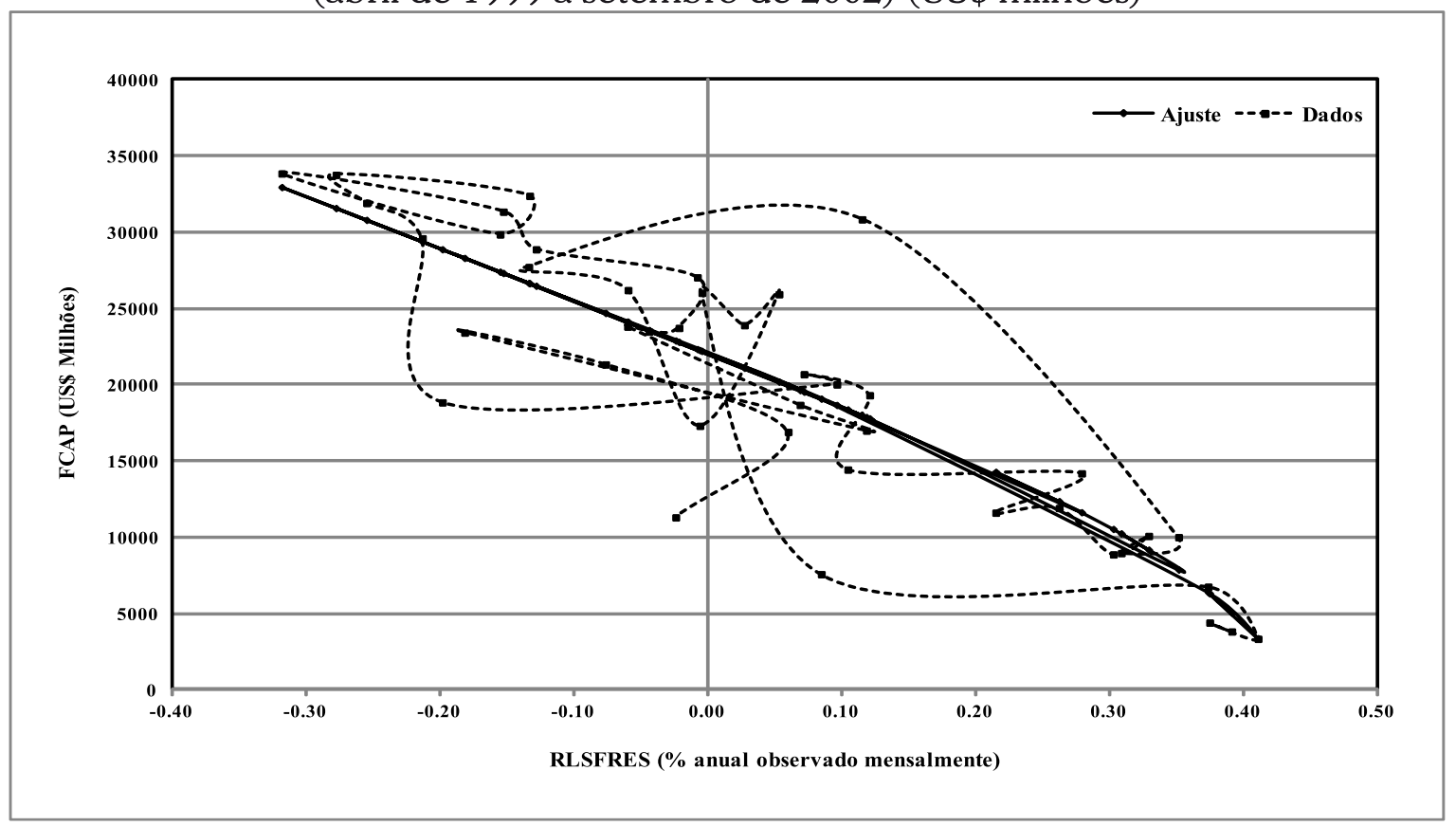

Fonte: Elaboração própria com dados do Banco Central do Brasil.

O terceiro período pode ser chamado como período de normalidade, pois não ocorreu nenhuma grande instabilidade ou crise internacional. Como proposto, nossa função continua apresentando um bom ajustamento, ou seja, a entrada de fluxo de capitais estrangeiros no país é tem uma relação clara e definida com a taxa de perda de reservas internacionais. O Gráfico 11 mostra o ajuste. 
Gráfico 11 - Estimação para o $3^{\circ}$ período (junho de 2003 a novembro de 2006) (US\$ milhões)

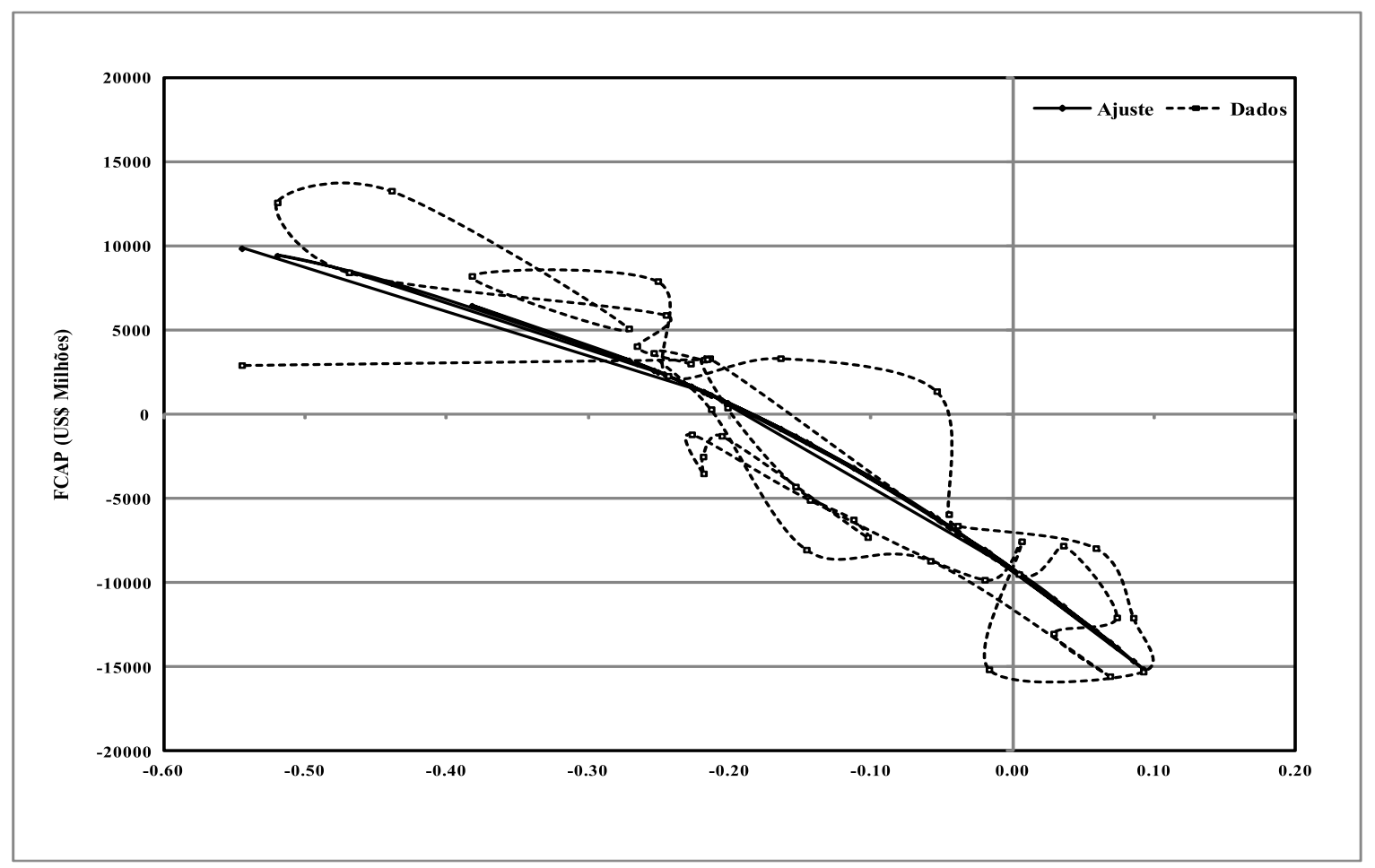

Fonte: Elaboração própria com dados do Banco Central do Brasil.

O quarto período, entre os períodos analisados, foi o período com maior turbulência internacional por causa da crise subprime nos USA. A sua magnitude e relevância foi comparada com aquela da bolsa de Nova Iorque em 1929. Neste período o Brasil aumentou demasiadamente seu nível de reservas internacionais, o que pode ser visto claramente no Gráfico 12. Neste período a entrada de fluxos estrangeiros alcançou seus maiores patamares, ficando um grande período em torno de US\$ 80 bilhões. 
Gráfico 12 - Estimação para o $4^{\circ}$ período (junho de 2007 a dezembro de 2010) (US\$ milhões)

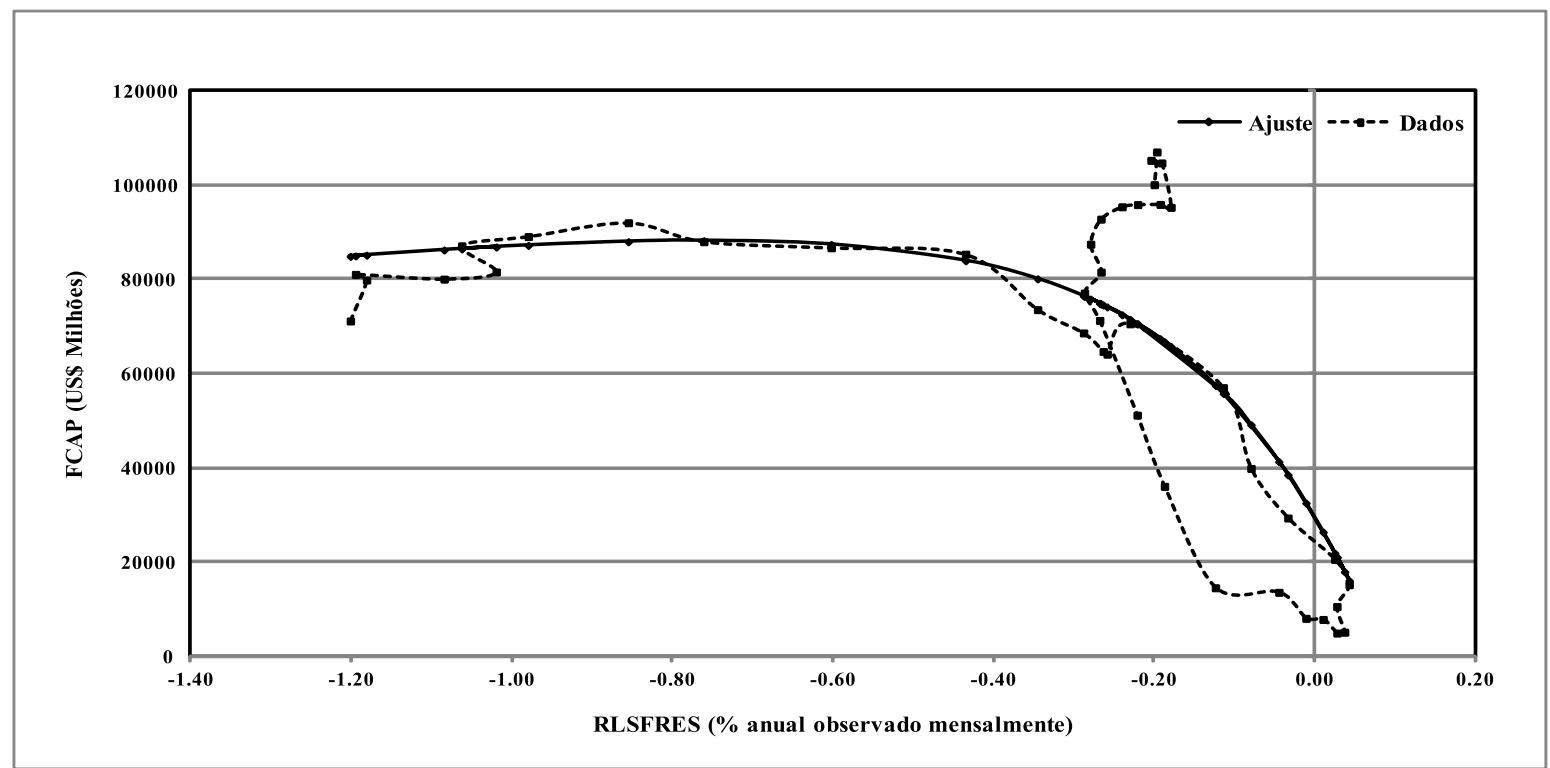

Fonte: Elaboração própria com dados do Banco Central do Brasil.

Os valores dos parâmetros da função hiperbólica com assíntotas oblíquas proposta na equação (22) foram estimados para cada período da análise e estão reportados na Tabela 2 .

Tabela 2 - Parâmetros estimados e testes nos períodos analisados

\begin{tabular}{ccccc}
\hline & $\mathbf{1}^{\mathbf{0}}$ Período & $\mathbf{2}^{\mathbf{0}}$ Periodo & $\mathbf{3}^{\mathbf{0}}$ Período & $\mathbf{4}^{\mathbf{0}}$ Período \\
\hline $\mathbf{a}_{\mathbf{1}}$ & 63.155 & 40.144 & 28.369 & 124.274 \\
$\mathbf{a}_{\mathbf{2}}$ & -28.265 & -78.833 & -60.069 & -294.430 \\
$\mathbf{a}_{\mathbf{3}}$ & 1.200 .000 .000 & 2.050 .000 .000 & 4.000 .000 .000 & 100.000 .000 .000 \\
$\mathbf{a}_{\mathbf{4}}$ & -200.000 .000 & -1.590 .000 .000 & -51.128 .772 & -1.000 .000 .000 \\
$\mathbf{a}_{\mathbf{5}}$ & 1.000 .000 .000 & 326.000 .000 & 1.410 .000 .000 & 9.000 .000 .000 \\
$\mathbf{L} \mathbf{L}_{\mathbf{u}}$ & $-403,930$ & $-411,727$ & $-400,916$ & $-483,728$ \\
$\mathbf{L n} \mathbf{L}_{\mathbf{r} \mathbf{1}}$ & $-405,636$ & $-426,573$ & $-409,248$ & $-497,159$ \\
$\mathbf{L n} \mathbf{L}_{\mathbf{r} \mathbf{2}}$ & $-410,370$ & $-412,373$ & $-402,826$ & $-501,619$ \\
$\boldsymbol{\lambda} \mathbf{1}$ & 3,4122 & $29,6904^{*}$ & $16,663^{*}$ & $26,8606^{*}$ \\
$\boldsymbol{\lambda \mathbf { 2 }}$ & $12,8792^{*}$ & 1,292 & 3,819 & $35,7822^{*}$ \\
\hline
\end{tabular}

Fonte: Elaboração própria.

Nota: *Significativo a $1 \%$.

Para testar se a função proposta no ajuste é linear utilizaremos o Likelihood ratio test - (LR). Especificamente, iremos testar as seguintes hipóteses: $H_{0}: a_{4}=a_{5}=0$ e também: $H_{0}^{\prime}: a_{3}=a_{4}=0$. Rejeitando ambas poderemos concluir que o melhor ajuste é o não linear. 
A razão de verossimilhança para o teste da primeira hipótese é denotada por " $\lambda 1$ " e para a segunda por " $\lambda 2$ ". Como mostra a Tabela 2, a primeira hipótese só não é rejeitada no primeiro período. Já a segunda hipótese não pode ser rejeitada no segundo e terceiro período. Analisando conjuntamente as duas hipóteses, somente no quarto período podemos rejeitar a hipótese que a função é uma reta. Assim no quarto período a hipótese se ajusta bem aos dados.

\section{Considerações Finais}

Os principais determinantes do fluxo de capital externo citados na literatura são: a taxa de retorno dos investimentos (sejam diretos, sejam em carteira), a percepção de risco do país (risco político ou risco soberano), taxa de câmbio, o grau de aversão ao risco dos investidores externos e a liquidez internacional de recursos.

Neste trabalho, analisamos como todas essas variáveis podem ser consideradas na agregação definida como a perda de reservas internacionais. Tal simplificação na determinação do fluxo pode ser explicada pela garantia que o país oferece de honrar os seus compromissos financeiros no futuro. Dessa forma, a variável "acúmulo de reservas" que em princípio é uma variável residual, acaba sendo uma importante ferramenta de controle de crises externas que os governos podem utilizar (e de fato utilizam).

Primeiramente proporcionamos um modelo teórico consumo-investimento de uma pequena economia aberta que demanda capital num período e que eventualmente pode devolver somente parte dos compromissos financeiros adquiridos do resto do mundo. Nesse caso ela sofre uma penalidade na sua função de utilidade que compensa o acréscimo do consumo no segundo período. Mostramos, através de uma simulação numérica no modelo proposto, que cada vez que o país aumenta o seu nível de reservas, o resto do mundo está disposto o a aumentar o seu fluxo de capital a taxas menores.

Uma vez verificada essa relação, procedemos a fazer o ajuste dessa curva pelo método de máxima verossimilhança o que também nos permite testar se de fato a relação é não linear. Um ajuste semelhante foi feito por Maldonado et al. (2007) para inserir o mercado de capital externo num modelo de Equilíbrio Geral Computável para analisar choques de políticas tarifárias.

Ajustes semelhantes podem ser feitos para outras economias em desenvolvimento (Argentina, México, Chile) obtendo-se resultados bastante análogos. Isto revela como as reservas internacionais de um país, ou mais precisamente, o acúmulo de elas pode ser um instrumento de estabilização em períodos de crise, deixando os investidores mais confiantes e a economia mais sólida em termos de potencial de honra de compromissos financeiros. 


\section{Referências}

AIZENMAN J.; MARION, N. The high demand for international reserves in the Far East: what's going on? Journal of the Japanese and International Economies, Duluth, US, v. 17, n. 3, p. 370-400, Sep. 2003.

BARBOSA L.; MEURER, R. Determinantes do investimento estrangeiro em carteira no Brasil de 1995 a 2009. In: ENCONTRO NACIONAL DE ECONOMIA, 38., 2010, Salvador. Anais... Salvador: ANPEC, 2010.

CHOI W. G.; SHARMA, S.; STROMQVIST M. Net capital flow, financial integration, and international reserves holdings: the recent experienxe of emerging markets and advanced economies. IMF Staff Papers, Washington, US, v. 56, n. 3, p. 516-540, Aug. 2009.

DURDU C. B.; MENDOZA E. G.; TERRONES M. Precautionary Demand for Foreign Assets in Sudden Stop Economies: An Assessment of the New Mercantilism. Journal of Development Economics, Amsterdam, NL, v. 89, p. 194-209, Jul. 2009.

JEANNE, O.; RANCIÉRE, R. The optimal level of international reserves for emerging market economies: formulas and applications. Economic Journal, Cambridge, US, v. 121, n. 555, p. 905-930, Sep. 2011.

KIM, Y. Causes of capital flows in developing countries. Journal of International Money and Finance, Amsterdam, NL, v. 19, n. 2, p. 235-253, Apr. 2000.

MALDONADO, W.; TOURINHO, O. A. F.; VALLI, M. Endogenous foreign capital flow in a CGE model for Brazil: The role of the foreign reserves. Journal of Policy Modeling, New York, US, v. 29, n. 2, p. 259-276, Mar. 2007.

PAULA, L. F.; OREIRO, J. L.; SILVA, G. Fluxos e controle de capitais no Brasil: avaliação e proposta de política. In: SICSÚ, J.; OREIRO, J. L.; PAULA, L. F. Agenda Brasil: políticas econômicas para o crescimento com estabilidade de preços. São Paulo: Manole, 2003.

SILVA, G. Poupança externa, controle de capitais e performance macroeconômica: teoria e evidência. 2004. 116 f. (Mestrado em desenvolvimento econômico) - Setor de Ciências Sociais Aplicadas, Universidade Federal do Paraná, Curitiba, 2004.

VAL V.; LIBÂNIO G. Volatilidade dos fluxos financeiros e fuga de capitais: uma análise exploratória da vulnerabilidade externa no Brasil. Belo Horizonte: CEDEPLAR/UFMG, 2010. (Texto para Discussão, 371).

Recebido em: 28/05/2011.

Aceito em: 14/05/2012. 